\title{
Chemical synthesis of nitric oxide in the stomach from dietary nitrate in humans
}

\author{
G M McKnight, L M Smith, R S Drummond, C W Duncan, M Golden, N Benjamin
}

\begin{abstract}
Background/Aims-It has been suggested that dietary nitrate, after concentration in the saliva and reduction to nitrite by tongue surface bacteria, is chemically reduced to nitric oxide (NO) in the acidic conditions of the stomach. This study aimed to quantify this in humans.

Methods-Ten healthy fasting volunteers were studied twice, after oral administration of $2 \mathrm{mmol}$ of potassium nitrate or potassium chloride. Plasma, salivary and gastric nitrate, salivary and gastric nitrite, and gastric headspace NO concentrations were measured over six hours.

Results-On the control day the parameters measured varied little from basal values. Gastric nitrate concentration was $105 \cdot 3$ (13) $\mu \mathrm{mol} / \mathrm{l}$ (mean (SEM), plasma nitrate concentration was $17.9 \quad(2 \cdot 4)$ $\mu \mathrm{mol} / \mathrm{l}$, salivary nitrate concentration $\mathbf{9 2 \cdot 6}$ (31.6) $\mu \mathrm{mol} / \mathrm{h}$, and nitrite concentration $53.9(22.8) \mu \mathrm{mol} / /$. Gastric nitrite concentrations were minimal ( $<1 \mu \mathrm{mol} / \mathrm{l})$. Gastric headspace gas NO concentration was $16.4(5.8)$ parts per million ( After nitrate ingestion, gastric nitrate peaked at 20 minutes at 3430 (832) $\mu \mathrm{mol} / \mathrm{h}$, plasma nitrate at $134(7 \cdot 2) \mu \mathrm{mol} / \mathrm{h}$, salivary nitrate at $1516.7(280.5) \mu \mathrm{mol} / \mathrm{l}$, and salivary nitrite at $761.5(187 \cdot 7) \mu \mathrm{mol} / \mathrm{l}$ after 20-40 minutes. Gastric nitrite concentrations tended to be low, variable, and any rise was non-sustained. Gastric NO concentrations rose considerably from $14.8(3 \cdot 1) \quad \mathrm{ppm}$ to $89.4 \quad(28.6) \quad \mathrm{ppm}$ $(p<0.0001)$ after 60 minutes. All parameters remained increased significantly for the duration of the study.

Conclusions-A very large and sustained increase in chemically derived gastric NO concentrations after an oral nitrate load was shown, which may be important both in host defence against swallowed pathogens and in gastric physiology.

(Gut 1997; 40: 211-214)
\end{abstract}

Keywords: nitric oxide, salivary nitrate and nitrite, stomach.

Nitric oxide (NO) is an important biological molecule that is responsible for cell signalling and host defence in a number of mammalian tissues. $^{12}$ It is now well established that mammalian cells produce NO from the amino acid L-arginine with a family of NO synthase enzymes.
We have recently proposed that NO may be synthesised by an alternative mechanism that relies on sequential reduction of nitrate. ${ }^{3}$ Dietary nitrate (principally derived from green, leafy vegetables) is absorbed from the stomach and proximal small intestine into the plasma and subsequently concentrated in saliva. ${ }^{45}$ Approximately $25 \%$ of dietary nitrate is recirculated. The dorsal surface of the tongue harbours large numbers of nitrate reducing facultative anaerobic bacteria, which rapidly reduce nitrate to nitrite under hypoxic conditions. ${ }^{67}$ There is therefore a high concentration of nitrite in saliva, which increases with oral nitrate intake. ${ }^{4}$ When swallowed, this nitrite is readily protonated under the acidic conditions of the stomach to form nitrous acid (acid dissociation constant $\mathrm{pK}_{\mathrm{a}} 3 \cdot 2-3 \cdot 4$ ), which in turn decomposes to various nitrogen oxides:

$$
\begin{array}{ll}
\mathrm{NO}_{2}{ }^{-}+\mathrm{H}^{+} & \rightarrow \mathrm{HNO}_{2}\left(\mathrm{pK}_{\mathrm{a}} \approx 3 \cdot 2-3 \cdot 4\right) \\
3 \mathrm{HNO}_{2} & \rightarrow \mathrm{H}_{2} \mathrm{O}+2 \mathrm{NO}^{2} \mathrm{NO}_{3}{ }^{-} \\
2 \mathrm{HNO}_{2} & \rightarrow \mathrm{H}_{2} \mathrm{O}+\mathrm{N}_{2} \mathrm{O}_{3} \\
\mathrm{~N}_{2} \mathrm{O}_{3} & \rightarrow \mathrm{NO}+\mathrm{NO}_{2}
\end{array}
$$

We have suggested that acidification of salivary nitrite is important in augmenting the antimicrobial effects of stomach acid and have shown that Candida albicans and Escherichia coli are much more susceptible to this combination than acid alone. ${ }^{3}$ Although it is not clear how acidified nitrite acts to kill micro-organisms, it is possible that $\mathrm{NO}$, or a product of $\mathrm{NO}$, is responsible as formation of this molecule from L-arginine has been shown to be important in host defence. ${ }^{8}$ The generation of NO in the human stomach has been demonstrated by measurement of $\mathrm{NO}$ in expelled gas after a carbonated drink in healthy subjects. ${ }^{9}$ The purpose of this study was to more clearly quantify NO synthesis in the human stomach and determine the temporal relation of chemical NO production after nitrate ingestion in healthy volunteers.

\section{Methods}

Ten healthy volunteers (six male; mean body weight $69 \mathrm{~kg}$ ), who were not taking any medication, were invited to take part (21-43 years). Local Ethics Committee approval was given for this study. Volunteers were fully informed and written consent obtained. Subjects were studied after overnight fasting on two separate occasions at least one week apart. The experimental protocol on each day was identical, other than oral administration on the test day of a $50 \mathrm{ml}$ solution containing $2 \mathrm{mmol}$ of potassium nitrate BP (Thornton and Ross, 
Huddersfield, UK), or on the control day, potassium chloride (BDH chemicals, Merck Ltd, Poole, Dorset, UK). After three hours, a low nitrate $(29 \mu \mathrm{mol}$ total), neutral $\mathrm{pH}$ drink (Complan) was given. The experimental order was randomly allocated.

After insertion of a fine bore nasogastric feeding tube (ET03 Medicina Ltd), blood, gastric headspace gas, gastric juice $(5 \mathrm{ml})$, and unstimulated saliva ${ }^{10}$ samples $(1-3 \mathrm{ml})$ were taken at 20 minute intervals for two hours and 30 minute intervals thereafter. To facilitate the aspiration of gastric contents, five minutes before sampling $50 \mathrm{ml}$ ambient air $(<10 \mathrm{ppb})$ was introduced via the nasogastric tube. The $\mathrm{pH}$ of gastric juice samples was measured and then the juices alkalinised with $50 \mu \mathrm{l} 5 \mathrm{M}$ $\mathrm{NaOH}$ to prevent further reduction of $\mathrm{NO}_{2}^{-}$. Nitrate and nitrite assays were performed by a modified Griess reaction, nitrate being first reduced on a copper coated cadmium column as previously described. ${ }^{11}$ Nitrite assays were performed in microwell plates and the diazo colour reaction detected at $540 \mathrm{~nm}$. NO in aspirated headspace gas was analysed after dilution $(10 \mathrm{ml}$ gastric gas diluted to $100 \mathrm{ml}$ total volume in NO impermeable container) with laboratory air to achieve final concentration less than $20 \mathrm{ppm}$ using a chemiluminescence meter (Thermo Electron Instruments, model 42A, Warrington, Cheshire, UK), which is calibrated with standard NO/nitrogen mixtures (MG Gas Products Ltd, Reigate,
UK). The chemiluminescence analyser was connected to a Maclab and Macintosh data acquisition system.

\section{Statistical analysis}

The results on the control and test days were compared using two way analysis of variance with repeated measures and post-hoc analysis using matched pairs $t$ tests; simple and Spearman rank correlation analysis. A value of $\mathrm{p}<0.05$ was considered significant.

\section{Results}

On the control day basal concentrations of plasma nitrate $(17.9(2 \cdot 4) \mu \mathrm{mol} / \mathrm{l})$, gastric nitrate $(105.3(23 \cdot 1) \mu \mathrm{mol} / \mathrm{l})$, salivary nitrate $(92.6(31.6) \mu \mathrm{mol} / \mathrm{l})$, and salivary nitrite $(53.9$ $(22.8) \mu \mathrm{mol} / \mathrm{l})$, gastric nitrite $(<1 \mu \mathrm{mol} / \mathrm{l})$ and headspace gas NO $(16.4(5.8) \mathrm{ppm})$ varied little over the six hour time course (Fig 1; Table).

In contrast, after oral administration of 2 mmol of potassium nitrate solution there were pronounced increases in plasma nitrate, gastric nitrate, salivary nitrate, salivary nitrite, and gastric headspace NO concentration. These remained considerably increased even at the end of the six hour study period (Fig 1; Table). Gastric nitrite concentrations tended to be low, variable, and any rise was not sustained although measurement was hampered by
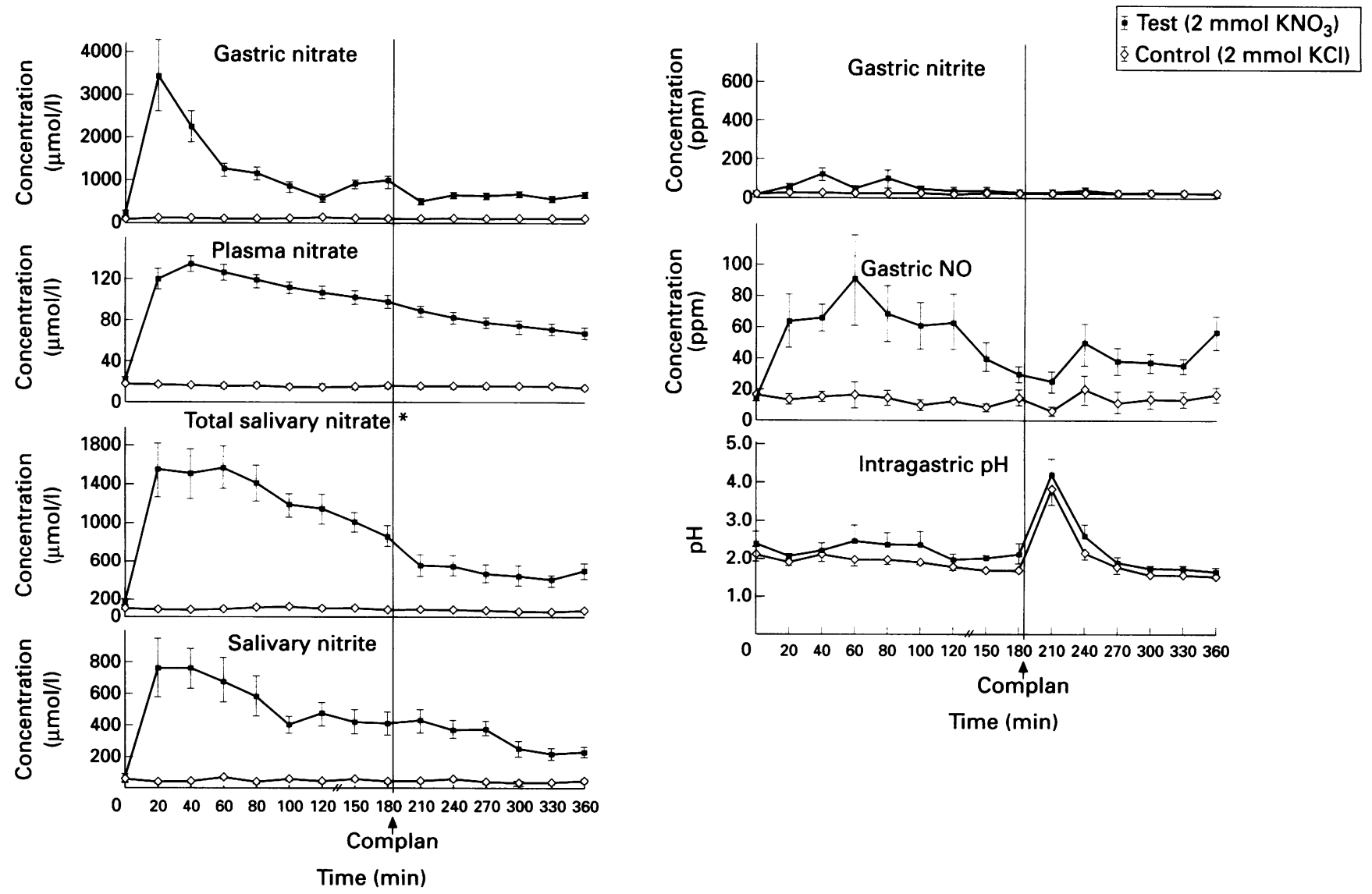

Figure 1: Effect of ingestion of nitrate on basal concentrations of plasma nitrate, gastric and salivary nitrates/nitrites, gastric NO (all p<0.001 ANOVA), and alteration of intraluminal $\mathrm{pH}$ with time and Complan ingestion, at 182 minutes represented by solid bar. ${ }^{\star}$ Represents total salivary nitrate secreting by salivary glands before reduction on tongue (measured as nitrate plus nitrite). Data shown as mean (SEM). 
Effect of an inorganic nitrate load (2 mmol) on plasma salivary and gastric nitrate, nitrite and nitric oxide concentrations

\begin{tabular}{llll}
\hline Sample & $\begin{array}{l}\text { Control (mean (SEM)) } \\
(\mu \text { moll })\end{array}$ & $\begin{array}{l}\text { Test (mean }(S E M)) \\
(\mu \text { moll })\end{array}$ & $\begin{array}{l}\text { Peak time } \\
(\text { mins })\end{array}$ \\
\hline Gastric nitrate & $133 \cdot 4(21 \cdot 2)$ & $3430 \cdot 1(832 \cdot 1)$ & 20 \\
Plasma nitrate & $17 \cdot 9(2 \cdot 4)$ & $134(7 \cdot 2)$ & 40 \\
Total salivary nitrate & $92 \cdot 6(31 \cdot 6)$ & $1516 \cdot 7(280 \cdot 5)$ & $20-40$ \\
Salivary nitrite & $53.9(22 \cdot 8)$ & $761.5(187 \cdot 7)$ & $20-40$ \\
Gastric nitrite & $0 \cdot 63(0.63)$ & $105 \cdot 3(32 \cdot 3)$ & 40 \\
Gastric NO (ppm) & $16.4(5 \cdot 8)$ & $89 \cdot 4(28 \cdot 6)$ & 60 \\
\hline
\end{tabular}

Gastric NO values are parts per million ( $\mathrm{ppm}$ ). Nitrate and nitrite values are $\mu \mathrm{mol} / \mathrm{l}$ as denoted.

difficulty in achieving a clear supernatant that would not interfere with absorption at $540 \mathrm{~nm}$. Due to the turbidity of some gastric juice samples even after repeated centrifugation, absorption readings were inappropriately high although there was no visibly detectable pink colour of the diazo reaction.

Peak gastric nitrate concentration occurred at the first measurement after intake $(20 \mathrm{~min})$, plasma values peaked at 40 minutes and gastric headspace NO concentration reached a peak at 60 minutes (Table). All remained significantly increased for the duration of the study $\left(p<10^{-8}\right.$ ANOVA; apart from gastric nitrite). The highest measured gastric headspace gas NO value was $291 \mathrm{ppm} 60$ minutes after intake of the nitrate solution.

Gastric acidity was not significantly affected by nitrate intake but dropped dramatically after the ingestion of Complan recovering by the next sampling time and thereafter decreasing (Fig 1). Although gastric NO was falling by the time the neutral drink was ingested, presumably parallel to the decline in salivary nitrate and nitrite concentrations, there was nevertheless a significant reduction in NO production when gastric $\mathrm{pH}$ rose after the drink and a significant recovery when gastric $\mathrm{pH}$ returned to basal conditions. This negative relation between gastric juice $\mathrm{pH}$ and stomach headspace gas NO concentration is shown in Figure $2\left(r_{\mathrm{s}}=-0.55 ; \mathrm{p}<0.01\right)$. There was no significant relation between stomach $\mathrm{NO}$ and salivary nitrite concentrations (control day $\left(r_{\mathrm{s}}=0.32 ; \mathrm{p}=0.024\right) ;$ test day $\left(r_{2}=0.46\right.$; $\mathrm{p}<0.001)$ ), nor were any of the measured variables different between sexes.

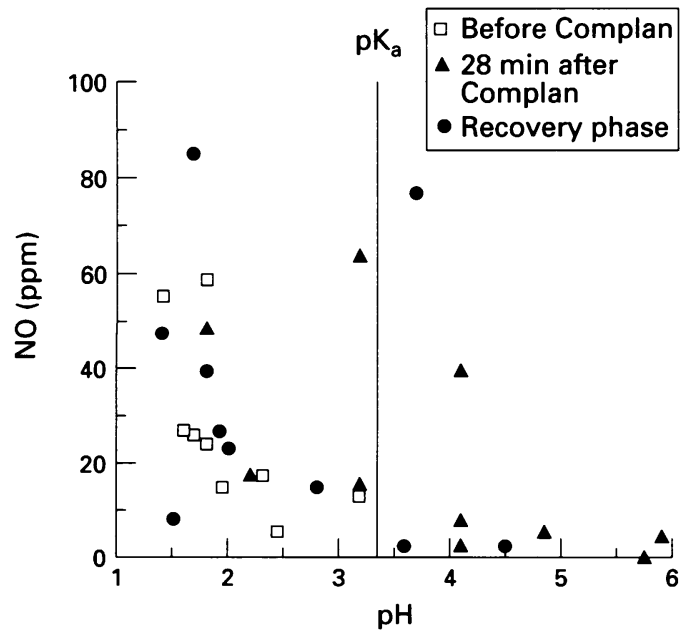

Figure 2: $p H$ dependency of gastric NO production. Spearman rank correlation $-0.55, p<0.01$.

\section{Discussion}

This study shows that very large concentrations of NO are generated in the stomach after an oral nitrate intake. The maximum concentration of NO was seen approximately 60 minutes after a dose of nitrate, which represents the average intake of an adult over one to two days in the UK. ${ }^{12}$ The mean concentration of NO at this time averaged $90 \mathrm{ppm}$; this is about 7000 times that found in exhaled breath. ${ }^{9}$ The concentrations of stomach headspace gas NO were considerably higher in our study than those previously reported (basal expelled gastric NO 800-6000 parts per billion). ${ }^{9}$ This may be due to dilution of gastric gas in the previous study with carbon dioxide generated from the carbonated drink used to induce belching. The higher values measured in this study may be an underestimate of true $\mathrm{NO}$ concentrations in the stomach as $\mathrm{NO}$ at this concentration will readily combine with oxygen to form $\mathrm{NO}_{2}$, albeit by second order kinetics, which is not measured by the chemiluminescence analyser we used. Furthermore, as we had to inject air into the stomach five minutes before sampling the concentration of $\mathrm{NO}$ in headspace gas may not have reached equilibrium with the gastric juice. In previous studies in vitro we found that headspace NO reaches equilibrium with the aqueous phase in a shaken closed vessel at about one hour. ${ }^{7}$

At six hours after nitrate intake the concentration remained considerably higher than baseline, suggesting a prolonged effect of dietary nitrate on stomach NO synthesis. The increased NO generation was associated with the expected rise in salivary nitrate and nitrite and the timecourse suggests that stomach NO synthesis derives from acidification of salivary nitrite, even though the correlation between stomach NO and salivary nitrite in individual subjects did not reach statistical significance. The concentration of stomach headspace NO was, however, associated with the degree of acidity in the stomach. During the course of the experiment, on both study days, stomach acidity increased initially, presumably due to the presence of a nasogastric tube. After ingestion of Complan there was a short lived reduction in acidity accompanied by reduction in nitric oxide generation even allowing for the expected fall in NO by this stage in the study. As gastric acidity recovered so NO generation followed and reached pre-meal levels and at the end of the study day NO levels were still significantly higher than on the control day. This is probably because of the persisting increase in plasma nitrate and thus assimilation into saliva even at the end of the study period.

Previous studies in vitro have shown that $\mathrm{NO}$ is generated when nitrite is acidified. The amount of NO generated in the stomach in vivo, however, greatly exceeds that expected from in vitro studies, suggesting another reducing agent such as ascorbate may be present in saliva or gastric juice to increase nitrite reduction to NO. ${ }^{7}$

We have previously suggested that salivary concentration of nitrate and subsequent rapid 
reduction to nitrite by lingual bacteria is a symbiotic process designed to serve a useful function. The very high and sustained concentrations of stomach NO generated by chemical reduction of salivary nitrite are likely to destroy or inhibit swallowed microbial pathogens. Several studies suggest that a variety of organisms are sensitive to this substance. Helicobacter pylori, which inhabits the mucus layer covering the mucosa (only a few microns thick) will be exposed to these high concentrations of NO that rapidly diffused through both lipid and aqueous mediums; the sensitivity of this organism to $\mathrm{NO}$ is as yet unknown.

In addition NO is known to be involved in the regulation of gastric mucosal blood flow ${ }^{13}$ and hence the preservation of mucosal integrity, gastric motility, ${ }^{14}$ and mucus production. Previous studies have suggested a role for NO in stimulated gastrin and gastric acid secretion ${ }^{15} 16$ although the high NO concentrations after nitrate intake did not reduce gastric $\mathrm{pH}$ in this study.

Although there has been continuing concern as regards the nitrosating potential of nitrate containing dietary constituents, epidemiological studies have failed to establish any causal association between gastrointestinal malignancy and dietary nitrate. ${ }^{17}$ While we have not attempted in this initial study to quantify nitrosamine production, in the normal acidic stomach the large amounts of NO that are generated and the very low gastric nitrite concentrations resulting from a nitrate load would suggest that nitrosamine formation is not favoured.

In summary, this study shows that dietary nitrate, by bacterial, as previously described, ${ }^{7}$ and chemical reduction, may generate very large concentrations of $\mathrm{NO}$ in the stomach, much greater than those generated by intrinsic NO synthase. ${ }^{18}$ The mechanism we describe may be extremely important in augmenting the antiseptic properties of gastric acid and modifying physiological gastric function. Additionally, the formation of $\mathrm{NO}$ in the stomach from acidified nitrate may be one of the mechanisms by which the nitrosating potential of nitrite and nitrate containing constituents of the diet is minimised. We believe that the mechanism of enterosalivary circulation of nitrate is designed to produce large concentrations of $\mathrm{NO}$ in the mouth and stomach and thus may have beneficial as well as possibly deleterious effects on human health.

This work was supported by a grant from the Ministry of Agriculture, Fisheries and Foods. The authors thank Dr N A the manuscript.

1 Moncada S, Higgs A. The L-Arginine-Nitric oxide pathway. NEngl f Med 1993; 329: 2002-12.

2 Anggard E. Nitric oxide: mediator, murderer and medicine. Lancet 1994; 343: 1199-206.

3 Benjamin N, O'Driscoll F, Dougall H, Duncan C, Smith L, Golden M, et al. Stomach NO synthesis. Nature 1994; 368: 502 .

4 Tannenbaum SR, Weisman M, Fett D. The effect of nitrate intake on nitrite formation in human saliva. Food Cosmet Toxicol 1976; 14: 549-52.

5 Spiegelhalder B, Eisenbrand G, Preussmann R. Influence of dietary nitrate on nitrite content of human saliva: possible relevance to in rivo formation of $\mathrm{N}$-nitroso compounds. Food Cosmet Toxicol 1976; 14: 545-8.

6 Sasaki T, Matano K. Formation of nitrite from nitrate at the dorsum linguae. f Food Hyg Soc fpn 1979; 20: 363-9.

7 Duncan C, Dougall H, Johnston P, Green S, Brogan R, Liefert $\mathrm{C}$, et al. Chemical generation of nitric oxide in the mouth from the enterosalivary circulation of dietary mouth from the enterosalivary circulatio.

8 Nathan C. Nitric oxide as a secretory product of mammalian cells. FASEB 1992; 6: 3051-64

9 Lundberg JON, Weitzberg E, Lundberg JM, Alving K. Intragastric nitric oxide production in humans: measurements in expelled air. Gut 1994; 35: 1543-6.

10 Granli T, Dahl R, Brodin P, Bockman OC. Nitrate and nitrite concentrations in human saliva: variations with salivary flow rate. Food Chem Toxicol 1989; 27: 675-80.

11 Green LC, Wagner DA, GlogowskiJ, Skipper PL, WishnokJS, Tannenbaum SR. Analysis of nitrate, nitrite, and $\left[{ }^{5} \mathrm{~N}\right]$ nitrate in biological fluids. Anal Biochem 1982; 26: nitrate

12 Knight TM, Forman D, Al-Dabbagh SA, Doll R. Estimation of dietary intake of nitrate and nitrite in Great mation of dietary intake of nitrate and nitrite
Britain. Food Chem Toxicol 1987; 25: 277-85.

13 Pique JM, Whittle BJR, Esplugues JV. The vasodilator role of endogenous nitric oxide in the rat gastric microcirculation. Eur f Pharmacol 1989; 174: 293-6.

14 Desai KM, Sessa WC, Vane JR. Involvement of nitric oxide in the reflex relaxation of the stomach to accommodate food or fluid. Nature 1991; 351: 477-9.

15 Stroff T, Plate S, Respondek M, Miller KM, Peskar BM. Protection by gastrin in the rat stomach involves afferent neurons, calcitonin gene-related peptide and nitric oxide. Gastroenterology 1995; 109: 89-97.

16 Bilski J, Konturek PC, Konturek SJ, Cieszkowski M, Czarnobilski K. Role of endogenous nitric oxide in the control of gastric acid secretion, blood flow and gastrin control of gastric acid secretion, blood flow and gastrin

17 Boeing H. Epidemiological research in stomach cancer: progress over the last ten years. $\mathcal{F}$ Cancer Res Clin Oncol 1991; 47: 133-43.

18 Kugler P, Drenckhahn D. Intrinsic source of stomach NO. Nature 1994; 370: 25-6. 